\section{Abendliches Fernsehen schädlich}

Sehen Kinder am Abend fern oder flimmern Gewaltszenen über den Bildschirm, sind Schlafstörungen vorprogrammiert. Dagegen scheint der Konsum gewaltloser Filme keinen Einfluss auf die Schlafqualität zu haben, solange Fernseher, Video oder PC nur tagsüber laufen, wie eine USamerikanische Studie an 617 Kindern im Alter von drei bis fünf Jahren zeigen konnte. Im Durchschnitt saßen die Kinder 72,9 Minuten täglich vor einem Bildschirm, davon 14,1 Minuten nach sieben Uhr abends. 18\% der Kinder hatten Schlafprobleme: In mindestens einem der abgefragten Parameter, wie Einschlaflatenz, nächtliches Erwachen, Albträume, schwerer Erweckbarkeit am Morgen und Tagesmüdigkeit, gab es an fünf bis sieben Tagen der Woche Probleme. Schwierigkeiten beim Einschlafen lagen dabei an der Spitze. Jede abendliche Stunde vor dem Bildschirm erhöhte den Schlafproblem-Score um 0,7 Punkte. Jede Stunde, auch tagsüber, in der die Kinder sich mit gewaltsamen Inhalten beschäftigten, erhöhte die Punktzahl um 0,4. Ohne Einfluss blieb es, wenn die Kinder sich tagsüber gewaltfreie Filme ansahen.Dr. Robert Bublak

Garrison MM et al. Pediatrics 2011; 128: 12935

\section{Welcher Laborwert verrät eine schwere Infektion?}

Die Zählung der Leukozyten bringt die Diagnostik bei einem fiebernden Kind mit Verdacht auf eine schwere Infektion nicht voran. Den höchsten diagnostischen Wert unter den Entzündungsmarkern zur $\mathrm{Ab}$ klärung einer schweren Infektion haben das C-reaktive Protein (CRP) und das Procalcitonin. In einer Metaanalyse schnitten beide Tests im Hinblick auf ihre Vorhersagewahrscheinlichkeit etwa gleich gut ab. Bei der Diagnostik einer schweren Infektionskrankheit sollten laut der Autoren allerdings die Grenzwerte entsprechend angepasst werden. So weist erst ein Procalcitoninwert über $2 \mathrm{ng} / \mathrm{ml}$ auf eine schwere Infektion hin (üblicher Normwert $<0,5 \mathrm{ng} / \mathrm{ml}$ ). Bei Werten $<0,5 \mathrm{ng} / \mathrm{ml}$ kann eine schwere Infektion sicher ausgeschlossen werden. Beim CRP sollte der Cut-off für eine schwere Infektion bei $80 \mathrm{mg} / \mathrm{l}$ angesetzt werden. Ein CRP $<20 \mathrm{mg} / \mathrm{l}$ schließt eine schwere Infektion aus (übliche Normwerte für CRP je nach Methode $<5$ bzw. $<10 \mathrm{mg} / \mathrm{l})$. Dr. Christine Starostzik

Cohen AT et al. Lancet 2008; 371: 387-94

\section{Senkung der Neugeborenensterblichkeit in Afrika}

In vielen Entwicklungsländern ist die neonatale Mortalität immer noch hoch. In einer randomisierten Studie wurde deshalb der Effekt einer Schulung von traditionellen Geburtshelferinnen durch einfache Maßnahmen bei Hausgeburten in unterversorgten Regionen in Sambia untersucht.

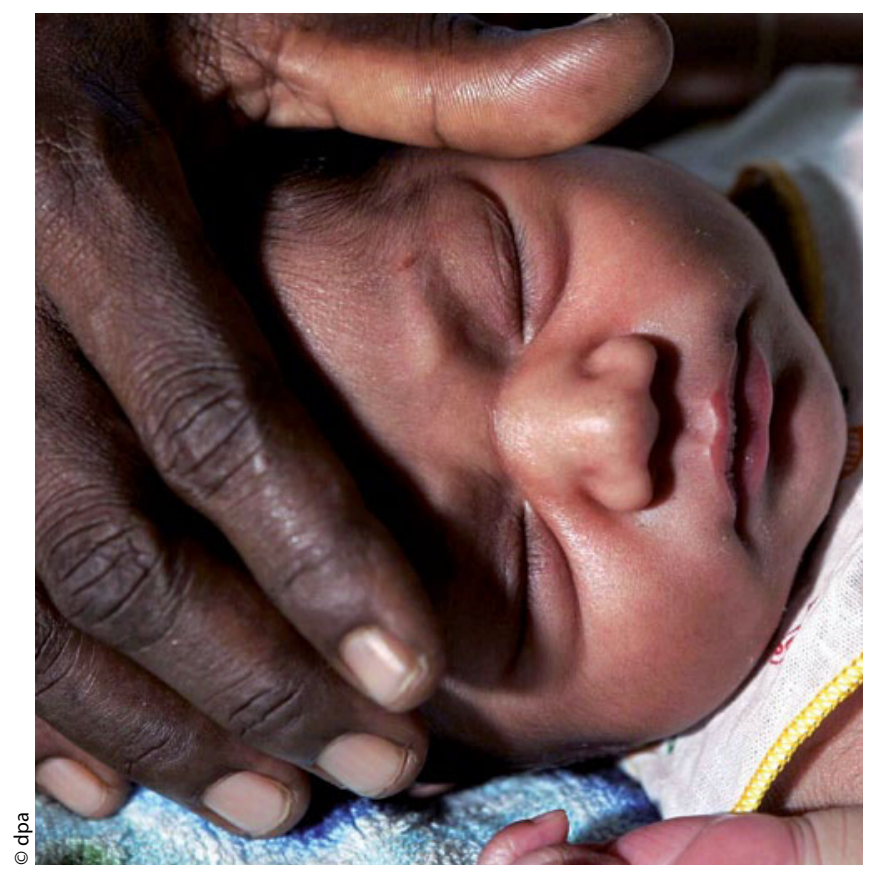

Nach einer Schulung der Hebammen überleben deutlich mehr Neugeborene. m Rahmen des prospektiven LUNESP-

Projekts (Lufwanyama Neonatal Survival Project; unterstützt durch die Universität Boston) wurden die nach alter Tradition praktizierenden Geburtshelferinnen randomisiert: entweder in eine Schulungsgruppe (standardisiertes Reanimationsprotokoll plus ggf. Amoxicillin) oder in eine Standardgruppe (Weiterführung der bisherigen Praxis). Insgesamt 127 „Hebammen“ und 3.559 Babys nahmen an der Studie teil.

Die Mortalität am Tag 28 lag bei der Schulungsgruppe um $45 \%$ niedriger als bei der Standardgruppe. Dabei konnte in den ersten 24 Stunden postnatal der größte Effekt festgestellt werden. Die Rate von Todesfällen infolge Asphyxie war bei der Schulungsgruppe sogar um $63 \%$ niedriger. Hauptunterschied im Vorgehen war das Freihalten der Luftwege (mit Absaugen, ggf. Bebeuteln), Abtrocknen und Wärmen der Neugebo- renen gegenüber einfachem Einwickeln der Kinder oder Abwischen der Nase. Bei der Anzahl von Totgeburten und Sepsis-bedingten Todesfällen konnte kein signifikanter Unterschied gesehen werden.

Gill CJ et al. Effect of training traditional birth attendants on neonatal mortality (Lufwanyama Neonatal Survival Project): randomised controlled study. BMJ 2011; 342: d346

Kommentar: Ein Training für traditionell praktizierende Hebammen in der Behandlung v. a. respiratorischer Störungen mit Absaugen und Maskenbeatmung kann zu einer signifikanten Senkung der neonatalen Mortalität in ländlichen Regionen Afrikas führen. Die einmalige Gabe von oralem Amoxicillin bei Infektionsverdacht senkte zwar die Sepsis-Sterblichkeit, erreichte aber keine statistische Signifikanz.

Dr. Ulrich Mutschler 